\title{
Um modelo de educação em saúde para o Programa Saúde da Família: pela integralidade da atenção e reorientação do modelo assistencial
}

\begin{abstract}
ALVES, V. S. A health education model for the Family Health Program: towards comprehensive health care and model reorientation, Interface - Comunic., Saúde, Educ., v.9, n.16, p.39-52, set.2004/fev.2005.

This paper aims at critically examining health education practices in the Family Health Program (PSF - Programa de Saúde da Família, Brazil) by building on the assumption that health policies are brought up to date in services by social actors and their everyday actions. The extent to which the principle of integrality is embodied in such practices is investigated, thus contributing to the debate on the grounds and limits of PSF's strategies towards reorienting its model of assistance by focusing on basic care. In the context of current Brazilian health policy, PSF has played a decisive role in building and consolidating the Brazilian Unified Health System (Sistema Único de Saúde - SUS). Health education practices and their underlying sanitary principles are historically reviewed in order to determine the rationale for such practices. The prevailing health education model, shown to be essentially at odds with the principle of integrality, is then characterized and analyzed against an emerging health education model - herein called "dialogic model" - the logic of which would be in accordance with the integrality of care.
\end{abstract}

KEY WORDS: Principle of integrality; Family Health Program; health education; care model.

Partindo da concepção de que as políticas de saúde se materializam nos serviços, mediante as ações de atores sociais e suas práticas cotidianas, este ensaio tem o objetivo de refletir sobre as práticas de educação em saúde no contexto do Programa Saúde da Família (PSF). Pretende-se apreciar a assimilação do princípio da integralidade nessas práticas e, desta maneira, contribuir para o debate sobre os alcances e limites da estratégia do PSF para a reorientação do modelo assistencial a partir da atenção básica. Na conjuntura atual da política de saúde brasileira, o PSF tem desempenhado papel estratégico para a construção e consolidação do Sistema único de Saúde (SUS). A partir de uma revisão histórica das práticas de educação em saúde e dos discursos sanitários a elas subjacentes, são reconstituídas as racionalidades determinantes de tais práticas. O modelo hegemônico de educação em saúde, em sua essência divergente do princípio da integralidade, é caracterizado e discutido em comparação a um modelo de práticas de educação em saúde emergente, denominado neste ensaio de modelo dialógico, cuja lógica manteria coerência com a integralidade da atenção.

PALAVRAS-CHAVE: Princípio da integralidade; Programa Saúde da Família; educação em saúde; modelo assistencial.

${ }_{1}^{1}$ Psicóloga, Instituto de Saúde Coletiva, Universidade Federal da Bahia (ISC/UFBA). <vaniasampa@yahoo.com.br> 


\section{Introdução}

A construção de um sistema de serviços de saúde democrático - universal, igualitário e integral - constitui um processo social e político que se realiza por meio de formulação de políticas públicas voltadas para a saúde, mas também, e essencialmente, no cotidiano dos serviços de saúde. A perspectiva de que as políticas de saúde se materializam na "ponta" do sistema, ou seja, mediante ação de atores sociais e suas práticas no cotidiano dos serviços (Pinheiro \& Luz, 2003), tem sido relevante para a reflexão crítica sobre os processos de trabalho em saúde, visando à produção de novos conhecimentos e ao desenvolvimento de novas práticas de saúde consoantes com os princípios e diretrizes do Sistema único de Saúde (SUS).

Para a construção do SUS é fundamental a reorientação do modelo assistencial vigente e hegemônico no país. Este modelo, resultante de uma combinação complementar e ao mesmo tempo antagônica do modelo médico-assistencial privatista e do modelo assistencial "sanitarista" (Paim, 2003a), dicotomiza assistência e prevenção. Paim (2003a) discute ser o modelo assistencial uma das áreas nas quais se concentram os mais relevantes entraves de um sistema de saúde. $\mathrm{O}$ autor relaciona os principais problemas de saúde identificados quanto ao modelo assistencial durante a VIII Conferência Nacional de Saúde, em 1986: "desigualdade no acesso ao sistema de saúde, inadequação dos serviços às necessidades, qualidade insatisfatória dos serviços e ausência de integralidade das ações" (Paim, 2003a, p.567). Esta realidade apontava não apenas a necessidade da reorientação do modelo assistencial, como também sinalizava a direção que esta reorientação precisava assumir de forma que se adequasse a proposta do SUS, em discussão. Dentre as bandeiras de luta pela Reforma Sanitária Brasileira, que se sustentavam nas críticas às práticas, às instituições e à organização do sistema de saúde, estava a bandeira da Integralidade (Mattos, 2001).

Na década de 1990 tem início a implementação da estratégia do Programa Saúde da Família (PSF) que, no contexto da política de saúde brasileira, deveria contribuir para a construção e consolidação do SUS. Tendo em sua base os pressupostos do SUS, a estratégia do PSF traz no centro de sua proposta a expectativa relativa à reorientação do modelo assistencial a partir da atenção básica (Brasil, 1997). Os alcances e os limites desta proposta têm alimentado discussões, cujos argumentos visitam desde estatísticas oficiais sobre a expansão do número de equipes até a reflexão crítica sobre as práticas de saúde desenvolvidas no contexto das unidades de saúde da família. Para acompanhar este debate, principalmente sob a ótica da segunda perspectiva, é essencial compreender o que traduz um modelo assistencial e, sobretudo, o que implica sua reorientação. Segundo Paim (2003a, p.568), modelo de atenção ou modelo assistencial "... é uma dada forma de combinar técnicas e tecnologias para resolver problemas e atender necessidades de saúde individuais e coletivas. É uma razão de ser, uma racionalidade, uma espécie de 'lógica' que orienta a ação".

Esta concepção de modelo assistencial fundamenta a consideração de que o fenômeno isolado de expansão do número de equipes de saúde da família implementadas até então não garante a construção de um novo modelo

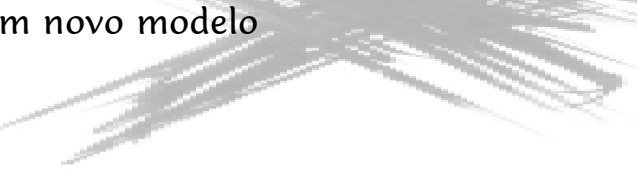


assistencial. A expansão do PSF tem favorecido a eqüidade e universalidade da assistência - uma vez que as equipes têm sido implantadas, prioritariamente, em comunidades antes restritas quanto ao acesso aos serviços de saúde. Entretanto, não se pode admitir, só pelas estatísticas, que a integralidade das ações deixou de ser um problema na prestação da atenção. Para tanto, faz-se necessário análises qualitativas do PSF (ou dos PSFs) em desenvolvimento nos municípios brasileiros, particularmente quanto às práticas de saúde e aos processos de trabalho cotidianos.

Este ensaio parte da concepção de modelo assistencial enquanto racionalidade e da pressuposição de que para a construção de um novo modelo é fundamental o desenvolvimento de novas racionalidades. Dentre os princípios e diretrizes do SUS, admite-se ser o da integralidade aquele que confronta incisivamente racionalidades hegemônicas no sistema - tais como o reducionismo e fragmentação das práticas, a objetivação dos sujeitos e o enfoque na doença e na intervenção curativa. Em face da relevância deste princípio para a reorientação do modelo assistencial, este ensaio tem o objetivo de refletir sobre as práticas de educação em saúde no contexto do PSF e a assimilação do princípio da integralidade nessas práticas.

\section{A integralidade e reorientação do modelo assistencial}

De acordo com o texto constitucional, complementado e aperfeiçoado pela Lei Orgânica da Saúde, a assistência à saúde pelo SUS deve abranger tanto as ações assistenciais ou curativas quanto, e prioritariamente, as atividades de promoção da saúde e prevenção de doenças (Carvalho \& Santos, 2002). Esta, entretanto, seria apenas uma das dimensões do conceito da integralidade. No campo da saúde, a integralidade tem sido reconhecida como expressão polissêmica, com seus muitos possíveis sentidos convergindo quanto a contraposição ao reducionismo, a fragmentação $e$ objetivação dos sujeitos (Mattos, 2001).

No que diz respeito à organização dos serviços e das práticas de saúde, a integralidade caracteriza-se pela assimilação das práticas preventivas e das práticas assistenciais por um mesmo serviço. Assim, o usuário do SUS não precisa dirigir-se a unidades de saúde distintas para receber assistência curativa e preventiva. No caso do PSF, a equipe de saúde da família está capacitada para executar desde ações de busca ativa de casos na comunidade adscrita, mediante visita domiciliar, até acompanhamento ambulatorial dos casos diagnosticados (tuberculose, hanseníase, hipertensão, diabetes, entre outras enfermidades) com o fornecimento de medicamentos. Seguindo o princípio da integralidade, as atividades de educação em saúde estão incluídas entre as responsabilidades dos profissionais do PSF.

Uma noção de integralidade também relacionada à organização dos serviços e das práticas encontra-se associada à necessidade de horizontalização dos programas de saúde. A política de saúde no Brasil tem sido marcada pela verticalização destas ações. As respostas governamentais às doenças, assim como as próprias doenças a serem incluídas na agenda governamental, tradicionalmente eram fundamentadas pelo saber técnico, particularmente pelo saber produzido pela saúde pública. Em conseqüência, estas respostas, que assumiam a forma de programas especiais de saúde 
pública (Paim, 2003a), caracterizavam-se pela "centralização de sua formulação, pela verticalização de sua implementação e por um caráter autoritário" (Mattos, 2003, p.49). Estas respostas atravessavam os serviços $e$ as práticas de saúde atropelando muitas vezes as necessidades específicas $e$ reais da população assistida. Neste nível, a assimilação da integralidade na organização dos serviços e das práticas repercutiria na identificação dos problemas de saúde a serem enfrentados pelas equipes de saúde a partir do horizonte da população atendida. No contexto da estratégia do PSF, esta perspectiva está de acordo com o princípio da vigilância da saúde, com o qual se propõe trabalhar. Sustentado em três pilares básicos: o territórioprocesso, os problemas de saúde e a intersetorialidade (Mendes, 1996), o princípio da vigilância da saúde contribui para a reorientação do modelo assistencial à medida que orienta uma intervenção integral sobre momentos distintos do processo saúde-doença (Paim, 2003b).

A integralidade contrapõe-se à abordagem fragmentária e reducionista dos indivíduos. O olhar do profissional, neste sentido, deve ser totalizante, com apreensão do sujeito biopsicossocial. Assim, seria caracterizada pela assistência que procura ir além da doença e do sofrimento manifesto, buscando apreender necessidades mais abrangentes dos sujeitos:

\footnotetext{
Não podemos aceitar que um médico responda apenas ao sofrimento manifesto do paciente (...) A atitude do médico que, diante de um encontro com o paciente motivado por algum sofrimento, aproveita o encontro para apreciar fatores de risco de outras doenças que não as envolvidas no sofrimento concreto daquele paciente, e/ou investigar a presença de doenças que ainda não se expressaram em sofrimento, ilustra um dos sentidos de integralidade. (Mattos, 2001, p.48-9)
}

Em conformidade com o princípio da integralidade, a abordagem do profissional de saúde não deve se restringir à assistência curativa, buscando dimensionar fatores de risco à saúde e, por conseguinte, a execução de ações preventivas, a exemplo da educação para a saúde. Uma situação ilustrativa é a de um atendimento a um paciente com crise hipertensiva, que além da administração da medicação necessária durante uma consulta médica seria orientado quanto à importância de uma alimentação hipossódica e de exercícios físicos regulares. Assistência e educação para saúde durante a consulta ambulatorial, sem que o paciente espere o momento de encontro do grupo dos hipertensos numa determinada data e horário para receber as referidas orientações: isto expressa integralidade da assistência.

Para que haja assimilação do princípio da integralidade na relação entre profissional de saúde e usuários, o que favoreceria uma intervenção em saúde para além da doença ou do corpo doente, com apreensão de necessidades mais abrangentes dos sujeitos, é necessário superar, ressalta Teixeira (2003), mais uma das modalidades de fragmentação no campo da saúde: a "cisão eu-outro" (p.90). Para o referido autor, trata-se da necessidade de superação do "monopólio do diagnóstico de necessidades" e de integração da "voz do outro" neste processo (Teixeira, 2003, p.91). 
Integrar ações preventivas, promocionais e assistenciais; integrar profissionais em equipes interdisciplinar e multiprofissional para uma compreensão mais abrangente dos problemas de saúde e intervenções mais efetivas; integrar partes de um organismo vivo, dilacerado e objetivizado pelo olhar reducionista da biomedicina, e reconhecer nele um sujeito, um semelhante a mim mesmo; nisto implica a assimilação do princípio da integralidade em prol da reorientação do modelo assistencial. Esta assimilação deve se processar cotidianamente nos encontros entre profissionais e usuários nos serviços de saúde, locus de exercício de racionalidades, sejam estas de manutenção do modelo assistencial vigente e hegemônico - marcadamente reducionista, biologicista, individualista, centrado na doença e orientado para a cura - ou de construção de um novo modelo assistencial - integral, humanizado e compromissado com o atendimento de necessidades e com a garantia do direito à saúde da população.

Educação em saúde: conceito e breve histórico

A educação em saúde constitui um conjunto de saberes e práticas orientados para a prevenção de doenças e promoção da saúde (Costa \& López, 1996). Trata-se de um recurso por meio do qual o conhecimento cientificamente produzido no campo da saúde, intermediado pelos profissionais de saúde, atinge a vida cotidiana das pessoas, uma vez que a compreensão dos condicionantes do processo saúde-doença oferece subsídios para a adoção de novos hábitos e condutas de saúde.

Dentre os diversos espaços dos serviços de saúde, Vasconcelos (1989; 1999) destaca os de atenção básica como um contexto privilegiado para desenvolvimento de práticas educativas em saúde. A consideração do autor justifica-se pela particularidade destes serviços, caracterizados pela maior proximidade com a população e a ênfase nas ações preventivas e promocionais. Para Mendes (1996), os serviços de atenção básica precisam apropriar-se de uma tecnologia de alta complexidade que envolve conhecimentos, habilidades $e$ técnicas, dentre as quais é possível reconhecer a educação em saúde.

Relacionando as funções de um médico de atenção básica, o autor destaca prestar atenção preventiva, curativa e reabilitadora, ser comunicador $e$ educador em saúde.

No âmbito do PSF, a educação em saúde figura como uma prática prevista $e$ atribuída a todos os profissionais que compõem a equipe de saúde da família. Espera-se que esta seja capacitada para assistência integral e contínua às famílias da área adscrita, identificando situações de risco à saúde na comunidade assistida, enfrentando em parceria com a comunidade os determinantes do processo saúde-doença, desenvolvendo processos educativos para a saúde, voltados à melhoria do auto-cuidado dos indivíduos (Brasil, 1997).

Em seus diferentes momentos históricos, os saberes e as práticas de educação em saúde foram impregnados por um discurso sanitário subjacente e fizeram uso de estratégias comunicacionais com estes discursos coerentes. $\mathrm{O}$ discurso higienista $e$ as intervenções normalizadoras tradicionalmente têm marcado o campo de práticas da educação em saúde. Para compreender a natureza deste discurso, Costa (1987) trata o tema da educação e saúde a 
partir de sua vinculação com o Estado e das relações de poder entre classes sociais. Nesta perspectiva e em consonância com a compreensão de Donangelo (1979) relativa à natureza social da prática médica, o autor reconhece as práticas de educação em saúde enquanto práticas sociais com propósitos ideológicos, políticos e econômicos. Desta maneira, mediante um discurso higienista e moralista, o Estado exerceria sua função de civilizar e moralizar a grande massa da população a fim de assegurar o desenvolvimento das forças produtivas. Em conformidade com os interesses das classes dirigentes do Estado e com objetivo de controle social sobre as classes subalternas, o discurso desenvolvido em torno da questão saúde no século XVIII foi essencialmente normalizador e regulador. De acordo com Costa (1987, p.7),

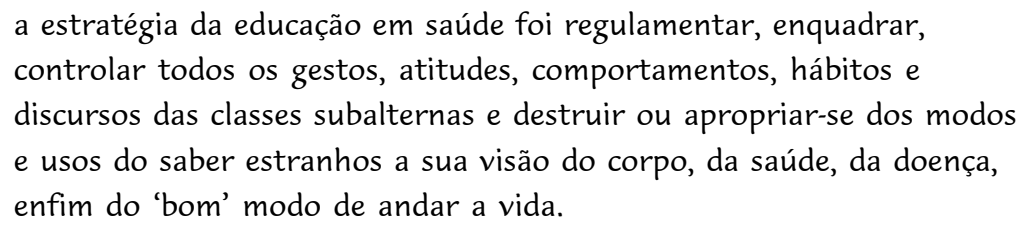

Na segunda metade do século XIX, o crescimento de cidades européias, em virtude da industrialização, favorece a precarização das condições de trabalho, moradia e nutrição das classes populares. Este cenário configurava uma ameaça às classes dominantes. Por um lado, pelo risco de rebelião dos populares, cuja aglomeração nos bairros poderia precipitar a organização política. Por outro, pelas epidemias que a estes inicialmente acometiam, associadas a condições de vida, atingindo em seguida as classes dominantes. Assim, justificavam-se as ações de disciplinamento das classes populares com difusão de regras de higiene e de condutas morais: o exercício do controle social e sanitário (Costa, 1987).

No Brasil do século XIX, o discurso sanitário segue a tendência européia, concentrando-se nas cidades e desenvolvendo-se em torno da moralidade e disciplinarização higiênica. O hospital, o hospício, a prisão e a escola despontam como espaços de atenção, cuidado e educação à saúde. Esta época é pontuada por Costa (1987) como de fortalecimento do saber técnico do profissional, exclusivo do poder da cura e controle sobre a doença, "rotulando as eventuais resistências e os saberes alternativos de cegueira política, ignorância do povo, má-fé dos charlatães" (p.11).

O percurso histórico das práticas e concepções de educação em saúde no Brasil é revisado por Smeke \&r Oliveira (2001). O primeiro momento abordado pelas autoras data do final do século XIX e início do século XX. Em virtude das necessidades de domínio sobre epidemias de varíola, peste, febre amarela, tuberculose, entre outras, nos grandes centros urbanos, visto que estas acarretavam transtornos para a economia agroexportadora, desenvolveram-se as primeiras práticas sistemáticas de educação em saúde. Estas voltavam-se principalmente para as classes subalternas e caracterizavam-se pelo autoritarismo, com imposição de normas e de medidas de saneamento $e$ urbanização com o respaldo da cientificidade. Acontecimento ilustrativo desse momento foi a polícia sanitária liderada por Osvaldo Cruz, que empregou recursos como a vacinação compulsória e vigilância sobre atitudes e moralidade dos pobres com a finalidade de controlar a disseminação de doenças. 
Estas práticas eram orientadas por um discurso biologicista, que reduzia a determinação do processo saúde-doença à dimensão individual, não assimilando as implicações das políticas sociais e das condições de vida e de trabalho para a saúde. O discurso biologicista propagava que os problemas de saúde eram decorrentes da não observância das normas de higiene pelos indivíduos e que a mudança de atitudes e comportamentos individuais garantiriam a resolutividade dos problemas de saúde. Este discurso predominou no campo da educação em saúde durante as décadas seguintes, podendo ser encontrado ainda hoje como orientador de práticas educativas.

A partir da década de 1940, algumas transformações começam a ser verificadas no campo da educação em saúde. Aos sujeitos que até então haviam sido culpabilizados individualmente pelos problemas de saúde que os acometiam e dos quais não se esperava mais do que a assimilação passiva das prescrições normativas dos profissionais de saúde, uma importância relativa passa a ser observada no sentido de envolvê-los no processo educativo. No início da década de 1960, com advento da Medicina Comunitária, verifica-se um apelo à participação da comunidade para a solução dos problemas de saúde nela vivenciados. Entretanto, por trás deste apelo de participação comunitária parece camuflar-se o mesmo discurso da culpabilidade dos sujeitos, com a ressalva da culpabilização passar da individualidade para a coletividade. As práticas de educação em saúde comunitárias partiam, então, do pressuposto de que as comunidades seriam as responsáveis pela resolução de seus problemas de saúde devendo, para isto, ser conscientizadas. Os determinantes sociais desses problemas, contudo, não eram levados em consideração.

Durante o regime militar, o campo da educação em saúde permaneceu inexpressivo em virtude da limitação dos espaços institucionais para sua realização. Verifica-se uma expansão dos serviços médicos privados e da medicina curativa, em detrimento dos serviços de atenção preventiva. Smeke $\varepsilon$ Oliveira (2001) admitem que durante esse período a educação em saúde correspondeu ao controle sobre os sujeitos.

Em contrapartida, este mesmo regime despertou uma resistência $e$ insatisfação na população que precipitou, ao longo da década de 1970, a organização de movimentos sociais que reuniram intelectuais e populares. Neste contexto, foram retomadas as proposta pedagógicas de Paulo Freire e profissionais de saúde revisaram suas práticas a partir da interlocução com as teorias das ciências humanas por um novo projeto em saúde. Estes movimentos deram início às críticas das práticas educativas autoritárias e normalizadoras apontando, ao mesmo tempo, para uma ruptura.

Dentre os movimentos que tiveram início na década de 1970 e que buscavam romper com a tradição autoritária e normalizadora da relação entre os serviços de saúde e a população, destaca-se o movimento da Educação Popular em Saúde (Vasconcelos, 2001). Este movimento foi precipitado pela insatisfação de alguns profissionais de saúde com os serviços oficiais; dirigindose para as periferias dos grandes centros urbanos e regiões rurais, aproximaram-se, assim, das classes populares e dos movimentos sociais locais. A aproximação favoreceu a convivência dos profissionais com a dinâmica do processo de adoecimento e cura no meio popular, bem como o confronto com a complexidade dos problemas de saúde nessas populações, o que levou muitos 
profissionais a buscarem a reorientação de suas práticas com a finalidade de enfrentar de forma mais global os problemas de saúde identificados.

A iniciativa dos profissionais em inserir-se em serviços de saúde que prestavam assistência às classes populares se deu integrada a projetos mais amplos, dentre os quais predominava a metodologia da Educação Popular (Vasconcelos, 2001). Assim sendo, esta metodologia foi assimilada pelo movimento dos profissionais constituindo seu elemento estruturante fundamental.

O movimento da Educação Popular em Saúde tem priorizado a relação educativa com a população, rompendo com a verticalidade da relação profissional-usuário. Valorizam-se as trocas interpessoais, as iniciativas da população e usuários e, pelo diálogo, buscam-se a explicitação e compreensão do saber popular. Esta metodologia contrapõe-se à passividade usual das práticas educativas tradicionais. O usuário é reconhecido como sujeito portador de um saber sobre o processo saúde-doença-cuidado, capaz de estabelecer uma interlocução dialógica com o serviço de saúde e de desenvolver uma análise crítica sobre a realidade e o aperfeiçoamento das estratégias de luta $e$ enfrentamento. Pela potencialidade desta metodologia, Vasconcelos (1999; 2001) vislumbra as experiências de Educação Popular como forma de superação do fosso cultural entre os serviços de saúde e a população assistida.

Nos locais em que a experiência tem sido desenvolvida verifica-se a "emergência de novos padrões de enfrentamento dos problemas de saúde marcados pela integração entre o saber técnico e o saber popular e pela mútua colaboração" (Vasconcelos, 1999, p.30). Em função deste resultado, o autor compreende a Educação Popular em Saúde não como uma atividade a mais a ser realizada pelos serviços de saúde, mas como uma estratégia capaz de reorientar as práticas de saúde.

A Educação Popular em Saúde tem convivido no Brasil com as modalidades de serviços hegemônicas. Desde a década de 1970, a despeito do amadurecimento da metodologia, as experiências em Educação Popular não deixaram de ser pontuais, alternativas e transitórias. De acordo com Vasconcelos (2001), a generalização dessas experiências constitui um desafio, apontando como dificuldade o embate com a racionalidade dos serviços oficiais $e$ a formação de recursos humanos.

O campo da educação em saúde tem sido, desde a década de 1970, profundamente repensado e verifica-se um relativo distanciamento das ações impositivas características do discurso higienista. Paralelamente, há uma ampliação da compreensão sobre o processo saúde-doença, que, saindo da concepção restrita do biologicismo, passa a ser concebido como resultante da inter-relação causal entre fatores sociais, econômicos e culturais. Neste momento, as práticas pedagógicas persuasivas, a transmissão verticalizada de conhecimentos, refletindo no autoritarismo entre o educador e o educando, e a negação da subjetividade nos processos educativos são passíveis de questionamentos. É também neste contexto que surge a preocupação com o desenvolvimento da autonomia dos sujeitos, com a constituição de sujeitos sociais capazes de reivindicar seus interesses (Smeke \& Oliveira , 2001).

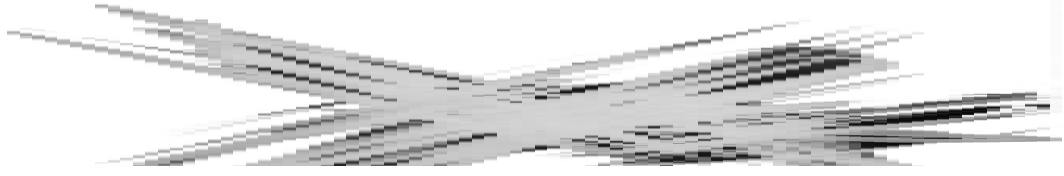


Entre dois modelos de práticas de educação em saúde A despeito da emergência de um novo discurso no campo da educação em saúde, prevalecem as práticas educativas hegemônicas. Da convivência entre as práticas emergentes e hegemônicas é possível delinear dois modelos de práticas de educação em saúde, que podem ser referidos como modelo tradicional e modelo dialógico. Estes se encontram em pólos extremos, sendo possível reconhecer modelos intermediários.

O modelo tradicional, historicamente hegemônico, focalizando a doença $e$ a intervenção curativa e fundamentado no referencial biologicista do processo saúde-doença, preconiza que a prevenção das doenças prima pela mudança de atitudes e comportamentos individuais (Smeke \& Oliveira, 2001; Chiesa \& Veríssimo, 2003). As estratégias desta prática educativa em saúde incluem informações verticalizadas que ditam comportamentos a serem adotados para a manutenção da saúde.

Os usuários são tomados como indivíduos carentes de informação em saúde (Briceño-Léon, 1996). Desta maneira, a relação estabelecida entre profissionais e usuários é essencialmente assimétrica, uma vez que um detém um saber técnico-científico, com status de verdade, enquanto o outro precisa ser devidamente informado. Desta maneira, a comunicação profissional-usuário caracteriza-se pelo caráter informativo, na qual o primeiro, assumindo uma atitude paternalista, explicita ao segundo hábitos e comportamentos saudáveis, o que fazer e como fazer para a manutenção da saúde. Pressupõe-se, ainda, que a partir da informação recebida os usuários serão capazes de tomar decisões para a prevenção de doenças e agravos, bem como poderão assumir novos hábitos e condutas.

Quanto à disseminação de informação em saúde, particularmente por meio de campanhas e veiculadas pelos meios de comunicação de massa, Rice \& Candeias (1989) falam do efeito temporário desta estratégia em relação a mudanças de hábitos e condutas. As autoras afirmam que a população não muda de comportamento em definitivo, mas apenas reage a um estímulo temporário. Com a supressão do estímulo, o comportamento tende à extinção.

A principal crítica a este modelo de educação, entretanto, tem sido referente a não consideração dos determinantes psicossociais e culturais dos comportamentos de saúde. Ao tomar os usuários como objeto das práticas educativas e carentes de um saber sobre a saúde, perde-se de vista que os comportamentos são orientados por crenças, valores, representações sobre o processo saúde-doença - todos estes representantes de formas outras de saber. Neste sentido, tem-se discutido sobre a consideração dos determinantes psicossociais e culturais nas práticas de educação em saúde (Gogna, 1998; Chor, 1999; Filgueiras \& Deslandes, 1999). Propõe-se que estas sejam sensíveis às necessidades subjetivas e culturais dos usuários. Para tanto, reconhece-se a necessidade de abandonar estratégias comunicacionais informativas e a adoção de uma comunicação dialógica.

A proposição de práticas educativas sensíveis às necessidades dos usuários insere-se no discurso emergente de educação em saúde - o modelo dialógico. Em oposição ao modelo tradicional, trabalha-se com a perspectiva de sujeitos das práticas de saúde (Ayres, 2001). Neste sentido, Briceño-Léon 
(1996) apresenta dois princípios básicos na orientação das ações de saúde. Primeiramente, é necessário conhecer os indivíduos para os quais se destinam as ações de saúde, incluindo suas crenças, hábitos e papéis, $e$ as condições objetivas em que vivem. O segundo princípio parte da premissa de que é preciso envolver os indivíduos nas ações, o que se contrapõe a sua imposição. $O$ autor pondera que apenas com a participação comunitária é possível assegurar sustentabilidade e efetividade das ações de saúde.

O modelo emergente de educação em saúde pode ser referido como modelo dialógico por ser o diálogo seu instrumento essencial. O usuário dos serviços é reconhecido sujeito portador de um saber, que embora diverso do saber técnico-científico não é deslegitimado pelos serviços. De acordo com BriceñoLéon (1996), em um modelo dialógico e participativo, todos, profissionais e usuários, atuam como iguais, ainda que com papéis diferenciados.

O objetivo da educação dialógica não é o de informar para saúde, mas de transformar saberes existentes. A prática educativa, nesta perspectiva, visa ao desenvolvimento da autonomia e da responsabilidade dos indivíduos no cuidado com a saúde, porém não mais pela imposição de um saber técnicocientífico detido pelo profissional de saúde, mas sim pelo desenvolvimento da compreensão da situação de saúde. Objetiva-se, ainda, que essas práticas educativas sejam emancipatórias. A estratégia valorizada por este modelo é a comunicação dialógica, que visa à construção de um saber sobre o processo saúde-doença-cuidado que capacite os indivíduos a decidirem quais as estratégias mais apropriadas para promover, manter e recuperar sua saúde (Chiesa E Veríssimo, 2003).

Como contexto das práticas educativas, considera-se que estas tanto podem ser formais e desenvolvidas nos espaços convencionais dos serviços, com realização das palestras e distribuição de cartilhas e folhetos, como também podem ser informais, desenvolvida nas ações de saúde cotidianas. Entretanto, dada a relevância da comunicação dialógica, valoriza-se o espaço das relações interpessoais estabelecidas nos serviços de saúde como contextos de práticas educativas. Nesse sentido, L'Abbate (1994) e Smeke \& Oliveira (2001) concordam quanto à compreensão de que todo profissional de saúde é um educador em saúde em potencial, sendo condição essencial a sua prática seu próprio reconhecimento enquanto sujeito do processo educativo, bem como o reconhecimento dos usuários enquanto sujeitos em busca de autonomia.

A partir do diálogo e intercâmbio de saberes técnico-científicos e populares, profissionais e usuários podem construir de forma compartilhada um saber sobre o processo saúde-doença. Este compromisso e vinculação com os usuários possibilita o fortalecimento da confiança nos serviços. Por esta circunstância, $o$ modelo dialógico tem sido associado a mudanças duradouras de hábitos e de comportamentos para a saúde, visto serem ocasionados não pela persuasão ou autoridade do profissional, mas pela construção de novos sentidos $e$ significados individuais e coletivos sobre o processo saúde-doença-cuidado.

Um modelo de educação em saúde para o Programa Saúde da Família Para a reorganização da atenção básica, a que se propõe a estratégia do PSF, reconhece-se a necessidade de reorientação das práticas de saúde, bem como de renovação dos vínculos de compromisso e de co-responsabilidade entre os 
serviços e a população assistida. Cordeiro (1996) avalia que o desenvolvimento de um novo modelo assistencial baseado nos princípios dd PSF não implica um retrocesso quanto à incorporação de tecnologias avançadas, conforme a compreensão inicial de que o PSF corresponderia a uma medicina simplificada destinada para os pobres; antes disso, tal proposta demanda a reorganização dos conteúdos dos saberes e práticas de saúde, de forma que estes reflitam os pressupostos do SUS no fazer cotidiano dos profissionais. Admite-se, nesta perspectiva, que o PSF "requer alta complexidade tecnológica nos campos do conhecimento e do desenvolvimento de habilidades e de mudanças de atitudes" (Brasil, 1997, p.9).

Pensar no PSF como estratégia de reorientação do modelo assistencial sinaliza a ruptura com práticas convencionais e hegemônicas de saúde, assim como a adoção de novas tecnologias de trabalho. Uma compreensão ampliada do processo saúde-doença, assistência integral e continuada a famílias de uma área adscrita são algumas das inovações verificadas no PSF.

Ayres (1996) observa que o reconhecimento de sujeitos está no centro de todas as propostas renovadoras identificadas no setor saúde, dentre as quais encontra-se a estratégia do PSF. De fato, os objetivos do programa, entre outros, incluem: a) humanização das práticas de saúde por meio do estabelecimento de um vínculo entre os profissionais e a população; b) a democratização do conhecimento do processo saúde-doença e da produção social da saúde; c) o desenvolvimento da cidadania, levando a população a reconhecer a saúde como direito; d) a estimulação da organização da comunidade para o efetivo exercício do controle social (Brasil, 1997). Notase, a partir desses objetivos, a valorização dos sujeitos e de sua participação nas atividades desenvolvidas pelas unidades de saúde da família, bem como na resolutividade dos problemas de saúde identificados na comunidade.

Quanto à reorientação das práticas de saúde, o PSF pretende oferecer uma atuação centrada nos princípios da vigilância da saúde (Brasil, 1997; Santana Er Carmagnani, 2001), o que significa que a assistência prestada deve ser integral, abrangendo todos os momentos ou dimensões do processo saúde-doença (Mendes, 1996). De acordo com o princípio da integralidade, o PSF deve ofertar prioritariamente assistência promocional $e$ preventiva, sem, contudo descuidar da atenção curativa e reabilitadora.

A abordagem da vigilância da saúde contempla o enfoque por problema, contrapondo-se, desta maneira, à atuação orientada por programas (Mendes, 1996). Enquanto este caracteriza-se pela definição apriorística dos problemas de saúde, traduzindo-se freqüentemente em intervenções verticalizadas, o enfoque por problemas parte do reconhecimento da área adscrita e de sua população para a identificação, descrição e explicação de seus problemas de saúde, para assim sobre eles intervir. Deste diagnóstico da situação de saúde local espera-se a participação ativa da comunidade, o que favorece o desenvolvimento da consciência sanitária pela possibilidade de compreensão sobre os problemas de saúde e seus determinantes.

As particularidades da estratégia do PSF remetem a um modelo de educação em saúde que seria mais coerente com os princípios do SUS incorporados pelo PSF, particularmente o da integralidade. Pelo nível de 
compromisso e responsabilidade esperado dos profissionais que compõem as equipes de saúde da família, pelo nível de participação desejado da comunidade na resolução dos problemas de saúde, pela compreensão ampliada do processo saúde-doença, pela humanização das práticas, busca da qualidade da assistência e de sua resolutividade, depreende-se que o modelo dialógico de educação em saúde corresponderia ao modelo mais pertinente para o contexto de atividades do PSF.

Ao nível da atenção preventiva, o PSF prevê o desenvolvimento de práticas de educação em saúde voltadas para a melhoria do auto-cuidado dos indivíduos. Estas devem ser desenvolvidas por todos os profissionais em seus contatos com indivíduos sadios ou doentes, conforme definição de suas atribuições básicas. Verifica-se, desta maneira, que a prática educativa no PSF não conta necessariamente com um espaço restrito e definido para seu desenvolvimento, antes disso adverte-se os profissionais que devem oportunizar seus contados com os usuários para "abordar os aspectos preventivos e de educação sanitária" (Brasil, 1997, p.15).

Educar para a saúde implica ir além da assistência curativa, significa dar prioridade a intervenções preventivas e promocionais. Deste modo, o desenvolvimento de práticas educativas no âmbito do PSF, seja em espaços convencionais, a exemplo dos grupos educativos, ou em espaços informais, como a consulta médica na residência das famílias em ocasião da visita domiciliar, expressa a assimilação do princípio da integralidade pelas equipes de saúde da família.

Dentre os modelos de educação em saúde, o modelo dialógico conformase à proposta da integralidade uma vez que favorece o reconhecimento dos usuários enquanto sujeitos portadores de saberes sobre o processo saúde-doença-cuidado e de condições concretas de vida. Nesta mesma direção, este modelo contribui para uma apreensão mais abrangente das necessidades de saúde dos sujeitos e na humanização da ação educativa, tornando-as mais sensíveis a seus destinatários.

Para tanto, reconhece-se, ainda, a necessidade da transformação da relação profissional-usuário para a construção de um modelo assistencial alternativo, capaz de acumular experiências contra-hegemônicas. Paim (2002, p. 363) pondera que "apesar da relevância da implantação do PSF faltam, contudo, evidências que apontem esse programa como estratégia suficientemente eficaz para a reorientação dos modelos assistenciais dominantes". Nesta empreitada, é fundamental a reformulação dos discursos e das racionalidades subjacentes.

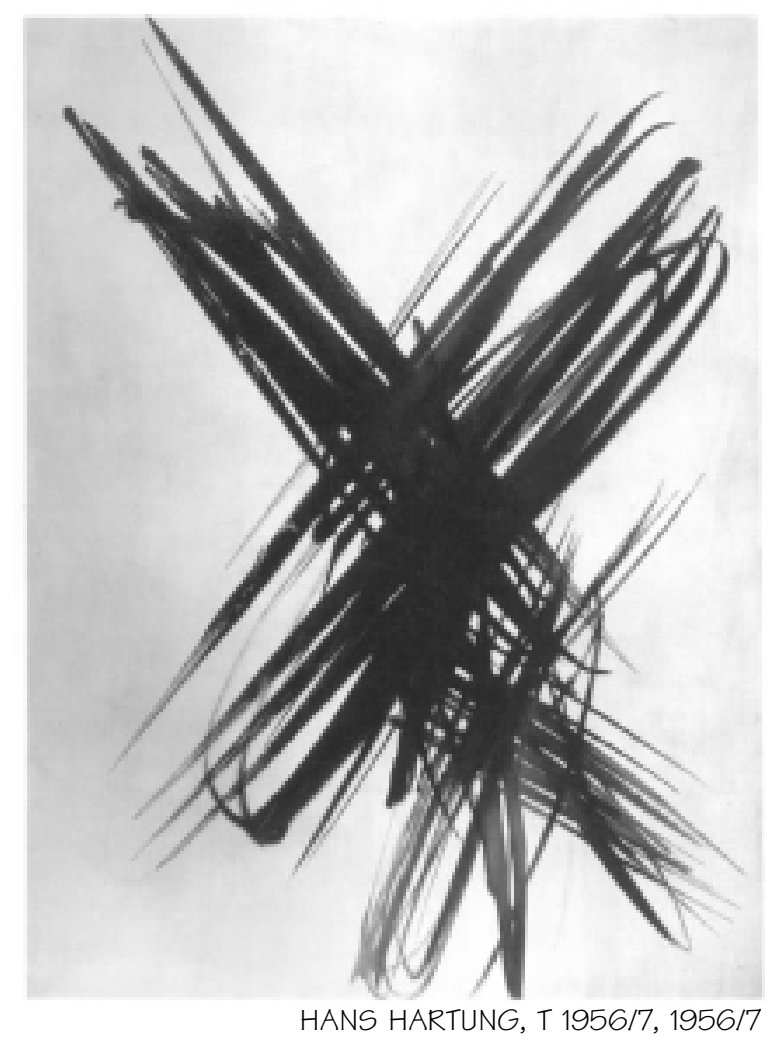


UM MODELO DE EDUCAÇÃO EM SAÚDE PARA O...

\section{Referências}

AYRES, J. R. C. M. Sujeito, intersubjetividade e práticas de saúde. Ciênc. Saúde Colet., v.6, n.1, p.63-72, 2001.

BRASIL. Ministério da Saúde. Saúde da família: uma estratégia para a reorientação do modelo assistencial. Brasília: Ministério da Saúde, 1997.

BRICEÑO-LÉON, R. Siete tesis sobre la educación sanitaria para la participación comunitaria. Cad. Saúde Pública, v.12, n.1, p.7-30, jan/mar., 1996.

CARVALHO, G. I.; SANTOS, L. Sistema Único de Saúde: comentários à lei orgânica de saúde (Leis n. 8.080/90 e n. 8.142/90). 3.ed. Campinas: Editora da UNICAMP, 2002. p.33-53.

CHIESA, A. M.; VERÍSSIMO, M. D. L. Ó. R. A educação em saúde na prática do PSF. Manual de enfermagem. Disponível em: <www.ids-saude.org.br/enfermagem>. Acesso em: 17 fev. 2003.

CHOR, D. Saúde pública e mudanças de comportamento: uma questão contemporânea. Cad. Saúde Pública, v.15, n.2, p.423-5, abr/jun., 1999.

CORDEIRO, H. O PSF como estratégia de mudança do modelo assistencial do SUS. Cad. Saúde da Família, v.1, n.1, p.10-5, 1996.

COSTA, M.; LÓPEZ, E. Educación para la salud. Madrid: Pirámide, 1996. p.25-58.

COSTA, N. R. Estado, educação e saúde: a higiene da vida cotidiana. Cad. Cedes, n.4, p.5-27, 1987.

DONANGELO, M. C. Medicina na sociedade de classes. In: DONANGELO, M. C.; PEREIRA, L. (Orgs.) Saúde e sociedade. São Paulo: Duas Cidades, 1979. p.29-68.

FILGUEIRAS, S. L.; DESLANDES, S. F. Avaliação das ações de aconselhamento: análise de uma perspectiva de prevenção centrada na pessoa. Cad. Saúde Pública, v.15, supl. 2, p.121-31, 1999.

GOGNA, M. Factores psicosociales y culturales en la prevención y tratamiento de las enfermidades de transmissión sexual. Cad. Saúde Pública, v.14, supl.1, p.81-5, 1998.

L’ABBATE, S. Educação em saúde: uma nova abordagem. Cad. Saúde Pública, v.10, n.4, p.481-90, out./dez., 1994.

MATTOS, R. A. Os sentidos da integralidade: algumas reflexões acerca de valores que merecem ser defendidos. In: PINHEIRO, R.; MATTOS, R.A. (Org.) Os sentidos da integralidade na atenção e no cuidado à saúde. Rio de Janeiro: UERJ/IMS: ABRASCO, 2001. p.39-64.

MATTOS, R.A. Integralidade e a formulação de políticas específicas de saúde. In: PINHEIRO, R.;

MATTOS, R. A. (Org.) Construção da integralidade: cotidiano, saberes e práticas em saúde. Rio de Janeiro: UERJ/IMS: ABRASCO, 2003. p.45-59.

MENDES, E. V. Um novo paradigma sanitário: a produção social da saúde. In: MENDES, E. V. Uma agenda para a saúde. São Paulo: Hucitec, 1996. p.233-300.

PAIM, J.S. Saúde da Família: espaço de reflexão e de práticas contra-hegemônicas? In: PAIM, J. S. Saúde, política e reforma sanitária. Salvador: CEPS/ISC, 2002. p.361-5.

PAIM, J.S. Modelos de atenção e vigilância da saúde. In: ROUQUAYROL. M.Z.; ALMEIDA FILHO, N. (Orgs.) Epidemiologia e saúde. 6.ed. Rio de Janeiro: MEDSI, 2003a. p.567-86.

PAIM, J.S. Gestão da atenção básica nas cidades. In: NETO, E.R.; BÓGUS, C.M. Saúde nos aglomerados urbanos: uma visão integrada. Brasília: Organização Pan-Americana da Saúde, 2003b. p.183-210.

PINHEIRO, R.; LUZ, M. T. Práticas eficazes x modelos ideais: ação e pensamento na construção da integralidade. In: PINHEIRO, R.; MATTOS, R. A. (Org.) Construção da integralidade: cotidiano, 
saberes e práticas em saúde. Rio de Janeiro: UERJ/IMS: ABRASCO, 2003. p.7-34.

RICE, M.; CANDEIAS, N. M. F. Padrões mínimos da prática da educação em saúde: um projeto pioneiro. Revista de Saúde Pública, v.23, n.4, p.347-53, 1989.

SANTANA, M. L.; CARMAGNANI, M. I. Programa Saúde da Família no Brasil: um enfoque sobre seus pressupostos básicos, operacionalização e vantagens. Saúde Soc., v.10, n.1, p.33-53, 2001.

SMEKE, E. L. M.; OLIVEIRA, N. L. S. Educação em saúde e concepções de sujeito. In: VASCONCELOS, E. M. (Org.) A saúde nas palavras e nos gestos: reflexões da rede educação popular e saúde. São Paulo: HUCITEC, 2001. p.115-36.

TEIXEIRA, R. R. O acolhimento num serviço de saúde entendido como uma rede de conversações. In: PINHEIRO, R.; MATTOS, R. A. (Orgs.) Construção da integralidade: cotidiano, saberes e práticas em saúde. Rio de Janeiro: UERJ/IMS: ABRASCO, 2003. p.89-111.

VASCONCELOS, E. M. Educação popular e a atenção à saúde da família. São Paulo: HUCITEC, 1999.

VASCONCELOS, E. M. Educação popular nos serviços de saúde. São Paulo: HUCITEC, 1989.

VASCONCELOS, E. M. Redefinindo as práticas de saúde a partir da educação popular nos serviços de saúde. In: VASCONCELOS, E. M. (Org.) A saúde nas palavras e nos gestos: reflexões da rede de educação popular e saúde. São Paulo: HUCITEC, 2001. p.11-9.

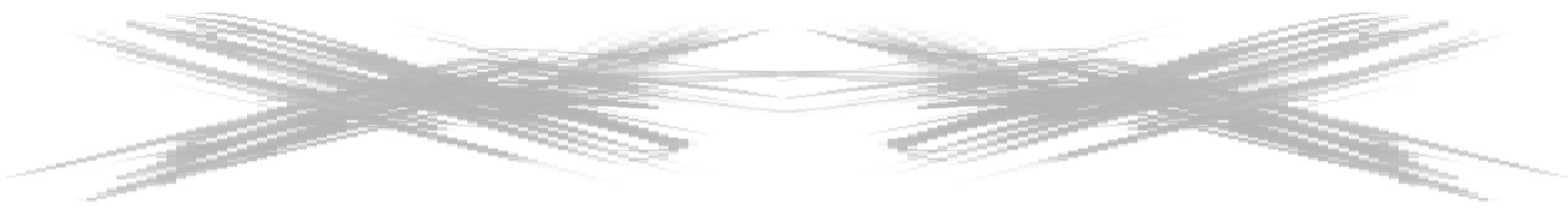

ALVES, V. S. Un modelo de educación en salud para el Programa Salud de la Familia: por la integralidad de la atención y reorientación del modelo asistencial, Interface - Comunic., Saúde, Educ., v.9, n.16, p.39-52, set.2004/fev.2005.

Partiendo de la idea de que las políticas de salud se materializan en los servicios, a través de las acciones de actores sociales y sus prácticas cotidianas, este ensayo tiene el objetivo de reflexionar sobre las prácticas de educación en salud en el contexto del Programa Salud de la Familia (PSF). Se pretende apreciar la asimilación del principio de integralidad en estas prácticas $y$, de esta manera, contribuir con el debate sobre los alcances y limitaciones de la estrategia del PSF para la reorientación del modelo asistencial a partir de la atención básica. En la actual coyuntura de la política de salud brasileña, el PSF desempeña un papel estratégico para la construcción y consolidación del Sistema único de Salud (SUS). A partir de una revisión histórica de las prácticas de educación en salud y de los discursos sanitarios subyacentes a ellas, se reconstruyen las racionalidades determinantes de tales prácticas. El modelo hegemónico de educación en salud, en esencia divergente del principio de integralidad, es caracterizado y discutido en comparación con un modelo emergente de prácticas de educación en salud, al que en este ensayo se denomina modelo dialógico, cuya lógica mantendría coherencia con la integralidad de la atención.

PALABRAS CLAVE: Principio de integralidad; Programa Salud de la Familia; educación en salud; modelo asistencial. 